\title{
Drug and alcohol addiction: new challenges
}

\author{
Jason Luty
}

\begin{abstract}
SUMMARY
There have been many developments in addiction psychiatry over the past decade. Some of these are political, such as preference for recovery-/ abstinence-based programmes. Prohibition is becoming increasingly unrealistic, especially considering the effective legalisation of recreational cannabis in Uruguay and two US states. Legal highs and diversion of prescribed drugs (such as methadone, gabapentinoids, methylphenidate and benzodiazepines) are now a major problem. Furthermore, diversion of opioid drugs that are prescribed for pain is reaching epidemic proportions, causing a significant change in the nature of patients being referred to addiction services.
\end{abstract}

\section{LEARNING OBJECTIVES}

- Be aware of political issues regarding abstinencebased treatment and prohibition.

- Be aware of risks and increased prevalence of diversion of drugs of misuse, especially opioid pain killers, gabapentinoids and benzodiazepines.

- Update knowledge of problems with methadone such as cardiac arrhythmias and diversion.

\section{DECLARATION OF INTERESTS}

None.

There have been several developments of relevance to practising addictions professionals since the publication of my previous articles in Advances (Luty 2003, 2006). In this article I review new challenges in the addictions field. In the next issue I will discuss developments in pharmacological treatments (Luty 2015, in press), after which I will address psychosocial treatment.

Worldwide, smoking is the second leading risk factor contributing to the total burden of disease, alcohol is third and drug misuse is nineteenth (Lim 2012) (Box 1). To put this into context, smoking is now the leading cause of preventable deaths (435000 deaths per year) in the USA, alcohol is the third (85000) and drug misuse is tenth (17000 deaths) (Mokdad 2004). Smoking cessation treatment tends to be provided by services separate from conventional drug and alcohol teams, so these will not be considered here.
There are significant political controversies relating to alcohol and drug addiction. For example, minimum pricing for alcohol has been postponed in Scotland and abandoned in the rest of the UK, despite overwhelming evidence for its effectiveness (Stockewell 2012; Gornall 2014; Sheron 2014). This inaction is presumably due to legal challenge and lobbying from the drinks industry (Babor 2003). In August 2013, Uruguay became the first country in modern times to legalise the production and sale of cannabis (marijuana). In February 2013, 18 states of the USA had passed laws allowing cannabis to be used for a variety of medical conditions, while in 2012 , voters in two states, Colorado and Washington State, approved policies legalising the sale and recreational use of marijuana.

\section{B0X 1 Worldwide ranking of causes of preventable death}

1 High blood pressure

2 Tobacco smoking

3 Alcohol use

4 Household air pollutants from solid fuels

5 Diet low in fruit

6 High body mass index (obesity)

7 High fasting plasma glucose (diabetes)

8 Childhood underweight (malnutrition)

9 Ambient particulate matter pollution (air pollution)

10 Physical inactivity

11 Diet high in sodium

12 Diet low in nuts and seeds

13 Iron deficiency

14 Suboptimal breastfeeding

15 High total cholesterol

16 Diet low in grains

17 Diet low in vegetables

18 Diet low in seafood omega-3 fatty acids

19 Drug use

20 Occupational injuries

\section{ARTICLE}

Jason Luty is consultant in addictions psychiatry at Borders Health in Scotland. He trained at the Maudsley Hospital, London, and spent 8 years as consultant in addictions at the South Essex Partnership NHS Trust, England. He has a $\mathrm{PhD}$ in pharmacology following a study of the molecular mechanisms of receptor desensitisation and tolerance and has published in the addictions field. Correspondence Dr Jason Luty, Borders Addiction Service, The Range, Tweed Road, Galashiels TD1 3EB, Scotland. Email: jason.luty@ yahoo.co.uk 
Principal changes to the addictions field, especially in the UK, include the development of non-statutory services and non-medical prescribers, the rise and fall of coercive treatment (such as the UK drug treatment and testing orders and drug rehabilitation requirements) and the increasing move away from residential treatment and brief admissions for detoxification. These political controversies will not be explored further here other than consideration of abstinence $v$. methadone maintenance treatment.

It is notable that the new diagnostic criteria in DSM-5 (American Psychiatric Association 2013) have removed the distinction between substance misuse and dependence by creating a continuum on which severity is determined by the number of clinical features from 2 (mild) to 6 or more (severe).

It is also salutary to commemorate the passing in 2012 of Professor Griffiths Edwards and Professor Hamid Ghodse. In a seminal report from 1976, Professor Edwards created the classification of alcohol dependence based on criteria including craving, withdrawal and tolerance which is still in use. Professor Ghodse founded the International Centre for Drug Policy at St George's, University of London.

\section{Abstinence v. maintenance}

Abstinence-based treatments comprise the majority of treatment options for substance misuse, with the prominent exception of opioid dependence. Detoxification is the process of reducing and stopping the use of addictive substances such as alcohol, often with some form of medical assistance (e.g. a prescription for benzodiazepines over 7-10 days). Stimulants (such as cocaine and amphetamine) do not require any prescribed medication to assist detoxification although, in practice, hypnotics or other sedative medication are often provided for a short time.

Subsequent editions of the UK Department of Health's clinical guidelines for substance misuse have oscillated between abstinence and maintenance treatment, with the prevailing emphasis (HM Government 2010) currently in favour of abstinence. This illustrates the cyclical nature of the debate and possibly the preference of incumbent governments.

Maintenance treatment is only recommended for opioid dependence. Methadone (or buprenorphine or lofexidine) may be used in short-term opioid detoxification (over 7-28 days). Alternatively, a maintenance prescription may be used whereby provision of a substitute drug (historically this has been methadone) continues over months or years with no requirement stop. (The term 'methadone maintenance' is often subsumed under the title 'harm reduction', which also includes other measures such as needle exchanges.)

There is overwhelming evidence that long-term maintenance treatment is consistently superior to detoxification (and other 'abstinence-based treatments') in the treatment of opioid dependence. For example, a report from British Columbia of over 25000 methadone treatment episodes showed that in only 1 in 40 episodes did the individual achieve a successful 'recovery' - abstinence from prescribed methadone with no treatment reentry within 18 months. The authors concluded that, 'the [vast] majority of patients attempting to taper from methadone maintenance treatment will not succeed' (Nosyk 2012). There are multiple comparable research reports (Amato 2011). Fewer than $10 \%$ of patients dependent on prescribed opioids were able to achieve abstinence for 3 months after a 4 -week taper using buprenorphinenaloxone (Weiss 2011). Almost identical results were sensationally reported from the UK in the press 6 years ago (Easton 2008). By contrast, around half of patients who are maintained on methadone can almost completely abstain from heroin (Gossop 2001; Hubbard 2003).

Regardless of the scientific evidence, the political battle between abstinence and harm reduction continues to rage. For example, in 2010 the newly elected UK government announced that substance misuse services should follow a 'recovery' model (HM Government 2010). Patients on opioid substitution therapy are 'encouraged' to reduce and stop all addictive drugs, including prescribed methadone, although there is no time limit suggested for this process. This illustrates the barriers to adoption of evidence-based practice.

\section{Misuse of prescribed opioids}

Misuse of opioids that were prescribed for pain (Table 1) was not a recognised problem 20 years ago. Indeed, the prevailing view was that 'strong' opioids such as morphine should be used more liberally, especially in acute settings. In practice, these agents were used primarily for severe acute pain in hospitals or for cancer pain in the community (Freynhagen 2013). There has been a significant increase in prescribing of high-potency opioids for non-cancer pain in recent decades, driven partly by aggressive marketing of these products (Freynhagen 2013). Illicit prescription opioids have become the second most common illicit substance of misuse after cannabis (Weiss 2011). In the USA in 2009, the use of a prescription opioid for non-medical reasons was 20 times more common than the use of heroin (Weiss 2011). 
There are now more deaths in the USA from prescription opioids than from heroin, and deaths from overdose following diversion and misuse of these products is the second leading cause of accidental death. In 2010, 5.1 million people over 12 years of age in the USA reported that they had used prescription opioids non-medically in the previous month (1.7\% of the entire population) (Substance Abuse and Mental Health Services Administration 2011).

Estimates suggest that $4 \%$ of all opioid doses prescribed in the USA are resold on the black market (Katz 2010). The overall societal cost of prescribed opioid misuse in the USA in 2007 was estimated at almost $\$ 56$ billion (US $\$$ in 2009) (Birnbaum 2011). Furthermore, there has been an $8 \%$ increase in patients seeking help for prescribed analgesic dependency in the UK over the past few years, with 154 deaths from tramadol (compared with 486 for methadone) in 2010-2011 (Ghodse 2011; Stannard 2013).

Expert reviews do not support the long-term prescription of opioids, especially at high doses, for many forms of non-cancer pain (Noble 2010). For example, a Cochrane review in 2009 of 10 randomised trials of opioids for osteoarthritis showed that most opioids conferred minimal benefit (Nüesch 2009). Up to 1 in 3 patients who are prescribed opioids for chronic pain show signs of misuse or dependence, especially those with a history of substance use disorder (Boscarino 2011).

An instrument has been developed (Webster 2005) that might help minimise the misuse of prescribed opioids. Called the Opioid Risk Tool, it involves simple precautions such as drug testing, prescribing contracts specifying the duration of prescription and non-response criteria, objective measures of improvement, regular review, frequent dispensing of small quantities, use of a single prescriber and a single, named pharmacy. However, the principal advice from published guidelines is that opioids should be stopped if they do not help at reasonable doses.

A randomised trial has been reported involving 653 treatment-seeking out-patients dependent on prescription opioids who were prescribed a buprenorphine-naloxone combination to achieve abstinence. Only $6.6 \%$ of patients became abstinent from prescription opioids in phase 1 of the trial, a 1-month buprenorphine-naloxone taper plus 2-month follow-up. Those who relapsed were admitted to phase 2 . These patients received 3 months of buprenorphine-naloxone stabilisation, followed by a 1-month taper and 2-month follow-up. Almost 50\% achieved a
TABLE 1 Relative potency (compared with morphine) and half-life of common prescribed opioids that are misused (oral formulation unless otherwise stated)

\begin{tabular}{|lcl|}
\hline Drug & Relative potency & Approximate half-life \\
\hline Morphine (oral) & 1 & $2-3 \mathrm{~h}$ (oral bioavailability $30 \%)$ \\
\hline Morphine (i.v./i.m.) & 3 & $2-3 \mathrm{~h}$ \\
\hline Methadone & $3-4$ & $16-60 \mathrm{~h}$ (half-life increases with chronic use) \\
\hline Codeine & 0.1 & $2-3 \mathrm{~h}$ (metabolised to morphine) \\
\hline Dihydrocodeine & 0.2 & $4 \mathrm{~h}$ (metabolised to morphine) \\
\hline Diamorphine (heroin) & $4-5$ & $2-3$ min (metabolised to morphine) \\
\hline $\begin{array}{l}\text { Morphine sulphate } \\
\text { slow-release }\end{array}$ & 1 & $\begin{array}{l}12-24 \mathrm{~h} \text { depending on formulation (when } \\
\text { ground or dissolved, morphine is released } \\
\text { immediately) }\end{array}$ \\
\hline Tramadol & & $5-7 \mathrm{~h}$ (partial $\mu$-opioid receptor agonist) \\
\hline Oxycodone & 0.1 & $3-4 \mathrm{~h}$ \\
\hline Oxymorphone & 1.5 & $7-9 \mathrm{~h}$ \\
\hline Hydromorphone & 7 & $2-3 \mathrm{~h}$ \\
\hline Buprenorphine & 5 & $\begin{array}{l}20-70 \mathrm{~h} \text { (partial } \mu \text {-opioid receptor agonist) - } \\
\text { used sublingually (low oral bioavailability) }\end{array}$ \\
\hline Pethidine (mepyridine) & 40 & $3-5 \mathrm{~h}$ \\
\hline
\end{tabular}

i.m, intramuscular; i.v., intravenous.

successful outcome 2 months after the gradual taper (patients received a substitute prescription for 4 months). (For information, patients were randomised to medication only or medication plus counselling sessions, although the results showed the counselling strategy provided no additional benefit). The trial showed excellent results using a substitute prescription for a modest time rather than rapid detoxification. However, these patients were all in receipt of prescribed opioids rather than using illicit drugs. They were also required to express a desire to come off their prescription in order to take part in the trial. They were therefore likely to have better social functioning and greater motivation than many patients dependent on illicit heroin (Weiss 2011).

\section{Cardiac arrhythmias and methadone}

Methadoneispostulated toproduceQT prolongation at high doses and in those with pre-existing cardiac disease. This is elegantly demonstrated in a large study of antidepressants in which methadone was included to demonstrate assay sensitivity. QT prolongation was dose-dependent even at modest doses of methadone (10-50 mg daily; Castro 2013). QT prolongation (typically over $450 \mathrm{~ms}$ in men and $470 \mathrm{~ms}$ in women) is thought to predispose to more serious, life-threatening arrhythmias such as torsades de pointes and ventricular fibrillation. However, the rate of serious cardiac events is uncertain in opioid-dependent patients. It is estimated that serious electrocardiogram (ECG) abnormalities affect $2-5 \%$ of these patients, 
while less serious abnormalities affect $10-30 \%$. Patients in methadone treatment are at risk of sudden death as a result of other cardiovascular risk factors, especially smoking, endocarditis and stimulant misuse. Other risk factors for ECG abnormalities include the patient's age, duration of methadone treatment, previous cardiovascular disease (including hypertension), male gender and concurrent medication (especially drugs that alter potassium balance). Hence, it is not possible to estimate the number, if any, of cardiac deaths that may be caused by methadone.

An expert panel of cardiologists recommended routinely asking patients about symptoms of syncope (such as faints and blackouts). The same panel also recommended that ECGs should be performed annually on all patients who are prescribed methadone, especially those on higher doses (perhaps arbitrarily taken to be doses more than $100 \mathrm{mg}$ ) (Krantz 2009). Unfortunately, a significant proportion of these ECGs are abnormal (estimated at between 25 and 50\%). Furthermore, an independent Cochrane review failed to find support for routine screening for cardiac arrhythmias in all patients on methadone (Pani 2013). Hence, it remains debatable whether annual ECG screening is justified for all patients on methadone or just those who are at high cardiac risk (such as those on daily methadone doses exceeding 100 mg; Department of Health 2007).

\section{Deaths from diverted methadone}

Deaths from methadone have been a recurrent problem - around half are caused by diverted prescribed methadone bought on the black market. In England in the 1990s, methadone was responsible for more deaths than illicit heroin. Subsequently, strict recommendations were introduced concerning supervised consumption of methadone, where patients take the drug under direct observation, usually by a pharmacist (Department of Health (England) 2007).

Despite variation in the practice of supervised consumption (Holland 2014), it has reduced the number of deaths by about fourfold (Strang 2010). In 2011, the National Programme on Substance Abuse Deaths at St George's, University of London analysed the 1883 drug-related deaths in the UK (Ghodse 2012). It reported that 455 (37\%) involved heroin/morphine (including 136 (11\%) where no other substance was implicated). By contrast, there were 308 deaths (25\%) involving methadone (including 87 (7\%) with no other substance). Only 131 of the 308 people whose deaths were methadone-related were in receipt of a methadone prescription at the time of death; 177
(58\%) presumably obtained methadone from illicit sources. In Scotland methadone was implicated in more than 237 deaths, compared with 221 deaths from heroin/morphine (National Records of Scotland 2013).

A well-known double-blind trial involving 193 intravenous opioid addicts revealed that $53 \%$ of the urine samples after 30 weeks were opioid-positive in those randomised to $80-100 \mathrm{mg}$ methadone, compared with $62 \%$ of those receiving $40-50 \mathrm{mg}$ (number needed to treat $\mathrm{NNT}=11$ ) (Strain 1999). However, this trial was performed in a research population who were starting treatment and it involved supervised consumption for all participants over the 30 weeks. A more recent US trial involving 1267 opioid-dependent patients supports many other reports by showing increased retention in treatment over 6 months for patients on methadone doses over $60 \mathrm{mg} /$ day $(80 \%$ v. $74 \%$ for doses $\leq 60 \mathrm{mg}$; $\mathrm{NNT}=16$ ), while doses over $120 \mathrm{mg}$ had $91 \%$ retention (NNT 6) (Hser 2013). However, it was unclear whether retention in treatment necessarily indicated a better outcome in terms of reduced opioid use, as the trial compared methadone with buprenorphine-naloxone and those that dropped out were not followed up. Unfortunately, in practice many patients will receive take-home doses of methadone after 3-6 months. Dispensing higher doses of methadone for patients to take home is likely to greatly increase the risk to other drug users.

\section{Legal highs}

'Legal highs' are newly available, synthetic psychoactive substances that are not regulated under current legislation such as the UK Misuse of Drugs Act 1971 (Table 2) (Faculty of Addictions Psychiatry 2014). Briefly, legal highs are taken for their temporary stimulant and euphoric effects in a similar manner to cannabis, ecstasy or ketamine. Side-effects and overdose produce symptoms similar to those of illegal stimulants. A Europewide survey in 2011 suggested that $5-10 \%$ of young people had taken a legal high in the previous year (compared with 25-50\% for cannabis, depending on age) (Gallup Organization 2011). Legal highs are usually bought on the internet or sold by the same dealers as cannabis and ecstasy. There are many hundreds of compounds: examples include 'meow meow' (mephedrone), GBL (gammabutyrolactone, an industrial solvent), BZP (benzylpiperazine) and salvia (an extract from the sage plant). The exact content of the illicit tablets or powder is extremely variable and some supplies may have completely different active agents when purchased at different times. 
Examples of legal highs (description and action) and related drugs of misuse

\begin{tabular}{|c|c|c|}
\hline Drug & Description & Approximate half-life \\
\hline Ecstasy/MDMA (3,4-methylenedioxy- $N$-methylamphetamine) & Stimulant & $8 \mathrm{~h}$ \\
\hline Ketamine & Dissociative anaesthetic; damaging to bladder & $2-3 h$ \\
\hline GHB (gamma-hydroxybutyric acid) & General anaesthetic & $20-30 \min$ \\
\hline Mephedrone ('meow meow') (4-methylmethcathinone; 4-MMC) & $\begin{array}{l}\text { Stimulant (incorrectly reported in the media as plant } \\
\text { food or fertiliser) }\end{array}$ & \\
\hline GBL (gamma-butyrolactone) & Industrial solvent; pro-drug for GHB & \\
\hline BZP (benzylpiperazine) & $\begin{array}{l}\text { Stimulant: initially developed as a veterinary } \\
\text { anthelmintic (anti-parasite) drug }\end{array}$ & $5 \mathrm{~h}$ \\
\hline Salvia (Salvinorin A), an extract from the sage plant & Hallucinogen & \\
\hline Mescaline (3,4,5-trimethoxyphenethylamine) & Hallucinogen: extract of peyote cactus & $6 \mathrm{~h}$ \\
\hline DMT or N,N-DMT (N,N-dimethyltryptamine) & $\begin{array}{l}\text { Hallucinogen: derivative of the essential amino acid } \\
\text { tryptophan, traditionally extracted from a mixture of } \\
\text { South American plants }\end{array}$ & \\
\hline N-bomb (25I-NBOMe) & Hallucinogen & $12-16 h$ \\
\hline Benzofury, 6-APB (6-benzofuran or 1-benzofuran-6-ylpropan-2-amine) & Stimulant (not a benzodiazepine) & \\
\hline Ivory Wave, 2-DPMP (2-diphenyImethylpiperidine, desoxypipradrol) & Stimulant & \\
\hline Mexxy, MXE (methoxetamine) & Dissociative anaesthetic (like ketamine) & $3-6 h$ \\
\hline
\end{tabular}

Testing a single psychoactive product to determine whether it is likely to cause harm typically costs around $£ 1$ million and takes about 1 year. This is highly onerous given the number of active chemicals used as legal highs. One approach to dealing with this problem is to require manufacturers and distributors to prove that their products pose a low risk of harm before they receive approval (Winstock 2010). Unfortunately, this is unlikely to be effective when products are ordered internationally on the internet and when they are being imported supposedly as plant food, solvents or industrial chemicals.

Treatment services for legal highs are being developed, although this is a very recent problem. Abstinence-based options are usually offered as for cannabis or stimulants.

\section{GHB}

GHB (gamma-hydroxybutyric acid) is a commonly misused, short-acting sedative drug that produces disinhibition and euphoria similar to the effects of alcohol. It is a typical example of a 'legal high' and is relatively simple to synthesise at home. It is often used in 'raves' and has been implicated in date rapes.

A withdrawal state with acute delirium has been reported and treatment with benzodiazepines or baclofen has been used (Zvosec 2011). GHB intoxication is a problem for accident and emergency departments, although long-term treatment strategies are being developed in a similar fashion to other legal highs.

\section{Benzodiazepine dependence}

By the mid-1970s, benzodiazepines had become the most widely prescribed psychotropic drug. Since the discovery in the 1970s of the dependence liability of benzodiazepines such as diazepam, most responsible expert guidelines have advised against the long-term prescribing of these agents. Similar advice is also given in relation to other sedative-hypnotics, such as zopiclone and zolpidem. Nevertheless, there remain a large number of people who are dependent on prescribed benzodiazepines and misuse of these drugs is widespread. For example, the British National Formulary (August 2014) states that benzodiazepines should only be used short term (2-4 weeks) in severe and disabling anxiety (not mild anxiety or insomnia) (Box 2). Despite

\section{B0X 2 Indications for benzodiazepine} prescription

- Benzodiazepines are indicated for the short-term relief (2-4 weeks only) of anxiety that is severe, disabling or causing the patient unacceptable distress, occurring alone or in association with insomnia or short-term psychosomatic, organic or psychotic illness

- The use of benzodiazepines to treat short-term 'mild' anxiety is inappropriate

- Benzodiazepines should be used to treat insomnia only when it is severe, disabling or causing the patient extreme distress

(British Medical Association 2014) 
repetition of this advice by virtually all responsible professional organisations, dependence on prescribed and illicit benzodiazepines is common. This may partly be due to determined pressure from individual patients to continue or restart prescriptions, especially patients with other substance use disorders.

Benzodiazepines are one of the largest classes of misused drugs. Estimates suggest that $2 \%$ of the adult populations of the USA and UK have used benzodiazepines regularly for more than 12 months - around half of these for 5-10 years. In 2010, the UK National Institute for Health and Care Excellence (NICE) estimated that 10-30\% of chronic benzodiazepines users were physically dependent on them (NICE 2010).

The idea that 'pharmacological' dependence on prescribed benzodiazepines is somehow different from other forms of 'addiction' is spurious. Benzodiazepine withdrawal usually produces uncomfortable but not life-threatening symptoms, with insomnia, anxiety, tremor, perspiration and tinnitus. This may persist for months and craving can continue for years. Consequently, many patients find that the benefits of cessation are not justified by the effort required to abstain, including chronic withdrawal symptoms.

\section{Are benzodiazepine detoxification or maintenance justified?}

It has yet to be demonstrated that either shortterm (detoxification) or long-term (maintenance) prescribing of benzodiazepines is justified following dependence on either illicit or prescribed benzodiazepines. Unlike heroin, alcohol or cocaine dependence, benzodiazepine misuse is not associated with high levels of acquisitive crime, regular injecting or physical complications such as cirrhosis, blood-borne virus infection or cardiovascular disease. Consequently, it is difficult to demonstrate significant benefits of treatment and it is hard to justify its cost (which is comparable to that of opioid substitution therapy in terms of staff time and dispensing arrangements). Many specialist addiction services therefore advise that detoxification should take place gradually in primary care or will provide a time-limited (3-month) community detoxification regime on a once-only basis.

The UK clinical guidelines on the management of substance misuse state:

'There is little evidence to suggest that longterm substitute prescribing of benzodiazepines reduces the harm associated with benzodiazepine misuse and there is increasing evidence that longterm prescribing (especially of more than $30 \mathrm{mg}$ diazepam equivalent per day) may cause harm' (Department of Health (England) 2007: p. 60).
Managing benzodiazepine detoxification involves transferring onto a long-term agent, typically diazepam, and reducing the dose by onequarter to one-eighth every 2 weeks, with frequent dispensing. In practice, this is almost always a protracted and uncomfortable process and may take years. Furthermore, there are high rates of relapse among patients who previously used illicit benzodiazepines, because of their low cost and relatively high availability (e.g. via the internet).

\section{The evidence base}

A meta-analysis of discontinuation from prescribed benzodiazepines reported that gradual dose reduction and brief interventions were superior to 'routine care' at achieving cessation (Parr 2008). The odds ratios were $\sim 6$ for dose tapering (although this was based primarily on one study by Oude Voshaar et al (2003)) and $\sim 4$ for brief interventions. Brief interventions might include sending letters to patients suggesting that they reduce their benzodiazepine prescriptions. The duration of withdrawal had a mean of 49 days (maximum 70 days), with variable periods of posttreatment follow-up, from 3 to 12 months. Typical abstinence rates at the end of treatment were $10 \%$ in the routine care group (maximum $15 \%$ ), $18 \%$ in the brief intervention group (maximum $40 \%)$ and $37 \%$ in the gradual reduction group (maximum 80\%). Oude Voshaar et al (2003) compared gradual (3-month) dose reduction with treatment as usual for 180 patients and reported cessation rates of $45 \%$ v. $29 \%$ at 3 months. Additional cognitive-behavioural therapy (CBT) did not improve outcomes. Unfortunately, 'routine care' in these trials is ill-defined. Furthermore, many of the patients were in receipt of prescribed benzodiazepines rather than obtaining these drugs from illicit suppliers (which is more typical of patients attending drug and alcohol services).

A meta-analysis (Parr 2008) found that three studies have shown brief interventions in primary care to be effective in achieving benzodiazepine abstinence among people on prescribed agents. However, the overall effectiveness remained modest, with $5 \%$ successful detoxification in the control group v. $22 \%$ in the treatment group. It also found that additional psychological therapy (based on CBT) significantly increased rates of abstinence: to $85 \%$ compared with routine care (48\%) or gradual dose reductions (54\%). However, the high rates of cessation in the enhanced treatment group fell to $50-60 \%$ at follow-up. These studies also involved primary care patients dependent on prescribed benzodiazepines. A further 14 studies showed little additional benefit of other 
adjuvant medication (11 different additional medications were tried, including melatonin, valproate, trazodone and paroxetine).

High-dose benzodiazepine users, who often also use other illicit drugs and/or alcohol, present a difficult problem because gradual benzodiazepine detoxification can often become long-term maintenance. There was little benefit of additional CBT over simple dose tapering (27\% v. 13\% discontinuation). However, patients who continued to use reported a halving in benzodiazepine consumption (Vorma 2003). Contingency management has also been used to address benzodiazepine misuse in patients on opioid substitution therapy, although the benefits are lost when the reinforcement is removed (Stitzer 1982).

\section{Long-term benzodiazepine prescription in anxiety disorders and alcohol dependence}

There have been intermittent suggestions that long-term benzodiazepine prescriptions are justified in generalised anxiety disorder, panic disorder and chronic insomnia - usually as a last resort (Starcevic 2012). Evidence to support their long-term use is controversial, especially as it is almost impossible to distinguish benzodiazepine withdrawal from relapse (rebound anxiety symptoms). The discovery that benzodiazepines cause dependence and pronounced withdrawal and that they are frequently misused means that there are few studies of long-term benzodiazepine use in anxiety disorders. Consequently, non-addictive antidepressants, especially selective serotonin reuptake inhibitors, are usually recommended in preference to benzodiazepines in anxiety disorders. Using antidepressants and benzodiazepines at the start of treatment for anxiety disorders will often relieve symptoms quickly, although the subsequent plan to discontinue the benzodiazepine after 6-10 weeks 'is not always easy. (Starcevic 2012). Hence, NICE guidelines state that 'benzodiazepines are associated with a less good outcome in the long term and should not be prescribed for the treatment of individuals with panic disorder' and also that 'benzodiazepines should not usually be used for more than 2 to 4 weeks for the treatment of generalised anxiety disorder' (NICE 2014).

A working group of the Royal College of Psychiatrists and the British Association for Psychopharmacology offers less Spartan advice regarding patients with anxiety symptoms:

'If there is no history of drug dependence, and positive indicative "lifestyle" factors are present, a conscious decision to continue benzodiazepine treatment may be more reasonable than the alternatives, provided the patient periodically attempts to slowly reduce the dosage at regular intervals and tries to stop altogether when or if possible' (Baldwin 2013).

However, the group explicitly states that longerterm prescribing is appropriate only for those with no history of drug dependence. In relation to anxiety disorders it states:

'There are clinical circumstances in which longerterm prescription of benzodiazepines might be considered desirable because the alternatives are probably worse than the continued use [...] In rare instances longer-term prescriptions [...] may be seen as a form of harm reduction in patients who would otherwise consume illicit benzodiazepines' (Baldwin 2013).

There is little evidence that long-term benzodiazepines assist abstinence in alcohol dependence.

\section{Summary}

Overall, treatment for benzodiazepine dependence remains unsatisfactory. This is partly due to the iatrogenic nature of the dependence, the investment required to detoxify patients, patients' ambivalence about stopping, poor outcome of treatment and also the relatively low harm associated with benzodiazepine dependence compared with alcohol or intravenous drug use.

\section{Gabapentin and pregabalin}

These anticonvulsant drugs are now being widely prescribed for pain, especially for more intractable neuropathic pain, to avoid the risk of dependence associated with opioids. Gabapentin and pregabalin enhance the action of the inhibitory neurotransmitter gamma-aminobutyric acid (GABA) in a similar manner to benzodiazepines. There are now many reports of misuse of pregabalin and gabapentin, which produce euphoria and intoxication similar to the effects of alcohol (Schifano 2011). This problem is only just emerging and there is no consensus on how it should be managed. However, restrictions are now being placed on the prescribing of pregabalin in the USA (Drug Enforcement Administration 2011).

\section{Conclusions}

Political issues have major bearing on treatment in substance misuse. This ranges from the stated preference for abstinence ('recovery') rather than methadone maintenance and funding for expensive and controversial treatments such as injectable opioids to political efforts to restrict sales of legal highs. In general, it would appear that obstacles preventing diversion of prescribed drugs of misuse and proliferation of legal highs are insurmountable - it is extremely difficult to legislate against a multitude of synthetic drugs 


\section{MCQ answers}

1 a 2 c 3 a $\quad 4$ c 5 e of misuse, and placing restrictive regulations on the use of opioid pain killers and benzodiazepines seems unlikely. Methadone has come under scrutiny again because of ECG abnormalities and high death rates from diverted prescriptions. However, the principal theme emerging over the past decade is the gradual failure of prohibition, especially with regard to diversion of prescribed medication and legalisation of cannabis.

\section{References}

American Psychiatric Association (2013) Diagnostic and Statistical Manual of Mental Disorders (5th edn) (DSM-5). APA.

Amato L, Minozzi S, Davoli M, et al (2011) Psychosocial combined with agonist maintenance treatments versus agonist maintenance treatments alone for treatment of opioid dependence. Cochrane Database of Systematic Reviews, 10: doi: 10.1002/14651858.CD004147.pub4.

Babor TF, Caetano R, Casswell S (2003) Alcohol: No Ordinary Commodity. Oxford University Press.

Baldwin DS, Aitchison K, Bateson A, et al (2013) Benzodiazepines: risks and benefits. A Reconsideration. Journal of Psychopharmacology, 27: 967-71

Birnbaum HG, White AG, Schiller M, et al (2011) Societal costs of prescription opioid abuse, dependence, and misuse in the United States. Pain Medication, 12: 657-67.

Boscarino JA, Rukstalis MR, Hoffman SN, et al (2011) Prevalence of prescription opioid-use disorder among chronic pain patients: comparison of the DSM-5 vs DSM-4 diagnostic criteria. Journal of Addictive Diseases, 30: 185-94.

British Medical Association, Royal Pharmaceutical Society (2014) British National Formulary (Aug issue). BMJ Group \& Pharmaceutical Press.

Castro VM, Clements CC, Murphy SN, et al (2013) OT interval and antidepressant use: a cross sectional study of electronic health records. BMJ, 346: f288.

Department of Health (England) and the devolved administrations (2007) Drug Misuse and Dependence: UK Guidelines on Clinical Management. Department of Health (England), Scottish Government, Welsh Assembly Government and Northern Ireland Executive.

Drug Enforcement Administration (2011) Drugs of Abuse: 2011 Edition. A DEA Resource Guide. DEA

Easton M (2008) Drug treatment - success or failure? BBC blog: Mark Easton's UK. BBC (http://www.bbc.co.uk/blogs/thereporters/ markeaston/2008/10/drug_treatment_officials_were.html). Accessed Sep 2014

Edwards G, Gross MM (1976) Alcohol dependence: provisional description of a clinical syndrome. BMJ, 1: 1058-61.

Faculty of Addictions Psychiatry (2014) One New Drug a Week: Why Novel Psychoactive Substances and Club Drugs Need aDifferent Response rrom Uk Treatment Providers (Faculty report FR/ AP/02). Royal College of Psychiatrists (http://www.rcpsych.ac.uk/pdf/FR\%20AP\%20 02_Sept2014.pdf).

Freynhagen R, Geisslinger G, Schug SA (2013) Opioids for non-cancer pain. BMJ, 346: 38-41.

Gallup Organization (2011) Youth Attitudes on Drugs: Analytical Report (Flash Eurobarometer 330). European Commission.

Ghodse H, Corkery J, Schifano F, et al (2011) Drug-Related Deaths in the UK: Annual Report 2011. International Centre for Drug Policy, St George's, University of London.

Ghodse H, Corkery J, Claridge H, et al (2012) Drug-Related Deaths in the UK: Aunnaul Report 2012. International Centre for Drug Policy, St George's, University of London.

Gornall J (2014) Under the influence: 2. How industry captured the science on minimum unit pricing. BMJ, 348: 18-23.
Gossop M, Marsden J, Stewart D, et al (2001) Outcomes after methadone maintenance and methadone reduction treatments: two-year follow-up results from the National Treatment Outcome Research Study. Drug and Alcohol Dependence, 62: 255-64.

HM Government (2010) Drug Strategy 2010 Reducing Demand, Restricting Supply, Building Recovery: Supporting People to Live a Drug Free Life. TSO (The Stationery Office).

Holland R, Maskrey V, Swift L, et al (2014) Treatment retention, drug use and social functioning outcomes in those receiving 3 months versus 1 month of supervised opioid maintenance treatment: results from the Super $C$ randomized controlled trial. Addiction, 109: 596-607.

Hser YI, Saxon AJ, Huang D, et al (2013) Treatment retention among patients randomized to buprenorphine/naloxone compared to methadone in a multi-site trial. Addiction, 109: 79-87.

Hubbard RL, Craddock SG, Anderson J (2003) Overview of 5-year followup outcomes in the Drug Abuse Treatment Outcome Studies (DATOS). Journal of Substance Abuse Treatment, 25: 125-34

Katz NP, Birnbaum HG, Castor A (2010) Volume of prescription opioids used nonmedically in the United States. Journal of Pain and Palliative Care Pharmacotherapy, 24: 141-4

Krantz MJ, Martin J, Stimmel B, et al (2009) OTc interval screening in methadone treatment. Annals of Internal Medicine, 150: 387-95.

Lim SS, Vox T, Flaxman AD, et al (2012) A comparative risk assessment of burden of disease and injury attributable to 67 risk factors and risk factor clusters in 21 regions, 1990-2010: a systematic analysis for the Global Burden of Disease Study 2010. Lancet, 380: 2224-60.

Luty $\mathrm{J}$ (2003) What works in drug addiction? Advances in Psychiatric Treatment, 9: 280-8.

Luty J (2006) What works in alcohol use disorders? Advances in Psychiatric Treatment, 12: 13-22.

Luty J (2015) Addiction: new pharmacotherapies. Advances in Psychiatric Treatment, 21: in press.

Mokdad AH, Marks JS, Stroup DF, et al (2004) Actual causes of death in the United States, 2000. JAMA, 291: 1238-45.

National Institute for Health and Care Excellence (2014) Anxiety (Amended): Management of Anxiety (Panic Disorder, with or without Agoraphobia, and Generalised Anxiety Disorder) in Adults in Primary, Secondary and Community Care. NICE.

National Institute for Health and Clinical Excellence (2010) Appraisal Consultation Document: Zaleplon, Zolpidem and Zopiclone for the Management of Insomnia. NICE.

National Records of Scotland (2013) Drug-Related Deaths in Scotland: Statistics of Drug-Related Deaths in 2012 and Earlier Years, Broken down by Age, Sex, Selected Drugs Reported, Underlying Cause of Death and NHS Board and Council Areas. National Records of Scotland.

Noble M, Treadwell JR, Tregear SJ, et al (2010) Long-term opioid management for chronic noncancer pain. Cochrane Database of Systematic Reviews, 1: CD006605.

Nosyk B, Sun H, Evans E, et al (2012) Defining dosing pattern characteristics of successful tapers following methadone maintenance treatment: results from a population-based retrospective cohort study. Addiction, 107: 1621-9.

Nüesch E, Rutjes AW, Husni E, et al (2009) Oral or transdermal opioids for osteoarthritis of the knee or hip. Cochrane Database of Systematic Reviews, 4: CD003115

Oude Voshaar RC, Gorgels WJMJ, Mol AJJ, et al (2003) Tapering off longterm benzodiazepine use with or without group cognitive-behavioural therapy: three-condition, randomised controlled trial. British Journal of Psychiatry, 182: 498-504.

Pani PP, Trogu E, Maremmani I, et al (2013) OTc interval screening for cardiac risk in methadone treatment of opioid dependence. Cochrane Database of Systematic Reviews, 6: CD008939.

Parr J, Kavanagh DJ, Cahill L, et al (2008) Effectiveness of current treatment approaches for benzodiazepine discontinuation: a metaanalysis. Addiction, 104: 13-24. 
Schifano F, D'Offizi S, Piccione M, et al (2011) Is there a recreational misuse potential for pregabalin? Analysis of anecdotal online reports in comparison with related gabapentin and clonazepam data. Psychotherapy and Psychosomatics, 80: 118-22.

Sheron N, Chilcoot F, Matthews L, et al (2014) Impact of minimum price per unit of alcohol on patients with liver disease in the UK. Clinical Medicine, 14: 396-403.

Stannard C (2013) Opioids in the UK: what's the problem? BMJ, 347: f5108.

Starcevic V (2012) Benzodiazepines for anxiety disorders: maximising the benefits and minimising the risks. Advances in Psychiatric Treatment, 18: $250-8$

Stitzer ML, Bigelow GE, Liebson IA, et al (1982) Contingent reinforcement for benzodiazepine-free urines: evaluation of a drug abuse treatment intervention. Journal of Applied Behavior Analysis, 15: 493-503.

Stockwell T, Auld MC, Zhao J, et al (2012) Does minimum pricing reduce alcohol consumption? The experience of a Canadian province. Addiction, 107: 912-20.

Strain EC, Bigelow GE, Liebson IA, et al (1999) Moderate- vs high-dose methadone in the treatment of opioid dependence: a randomized trial. JAMA, 281: 1000-5.
Strang J, Hall W, Hickman M, et al (2010) Impact of supervision of methadone consumption on deaths related to methadone overdose (1993-2008): analyses using OD4 index in England and Scotland. BMJ, 341: $c 4851$

Substance Abuse and Mental Health Services Administration (2011) Results from the 2010 National Survey on Drug Use and Health: Summary of National Findings. US Department of Health and Human Services.

Vorma H, Naukarinen H, Sarna S (2003) Long-term outcome after benzodiazepine withdrawal treatment. Drug and Alcohol Dependence, 70: 309-14.

Webster LR, Webster RM (2005) Predicting aberrant behaviors in opioidtreated patients: preliminary validation of the Opioid Risk Tool. Pain Medicine, 6: 432-42.

Weiss RD, Potter JS, Fiellin DA, et al (2011) Adjunctive counseling during brief and extended buprenorphine-naloxone treatment for prescription opioid dependence: a 2-phase randomized controlled trial. Archives of General Psychiatry, 68: 1238-46.

Winstock AR, Ramsey JD (2010) Legal highs and the challenges for policy makers. Addiction, 105: 1685-7.

Zvosec DL, Smith SW, Porrata T, et al (2011) Case series of 226 gammahydroxybutyrate-associated deaths: lethal toxicity and trauma. American Journal of Emergency Medicine, 29: 319-32.

\section{MCOs}

Select the single best option for each question stem

1 Of the following list, the most common cause of avoidable death in the world is:

a tobacco

b alcohol

$c$ heroin

d cocaine

e cannabis.

2 The second most common class of illicit drugs of misuse in the USA in 2011 was:

a cannabis

b cocaine

c prescription opioids

$d$ heroin

e ketamine.
3 Over the past decade, supervised consumption has reduced deaths from methadone overdose by about:

a fourfold

b tenfold

$c$ half

d $10 \%$

e twentyfold.

4 The proportion of the adult populations of the USA and UK estimated to have used benzodiazepines regularly for 12 months or over is:

a $20 \%$

b $0.1 \%$

c $2 \%$

d $40 \%$

e $50 \%$.
5 Regarding 'legal highs', testing a single compound to determine whether it is likely to cause harm:

a typically costs $£ 10000$ and takes 1 month

b typically costs $£ 1000$ and takes 6 months

c typically costs $£ 100000$ and takes 6 months

d typically costs $£ 100000$ and takes 1 year

e typically costs $£ 1000000$ and takes 1 year. 